\title{
Üreter Taşlarının Minimal İnvaziv Tedavisi
}

\author{
Abdulkadir Tepeler, Muzaffer Akçay, Abdullah Armağan
}

Bezmialem Vakıf Üniversitesi, Tıp Fakültesi, Üroloji Anabilim Dalı, İstanbul

\begin{abstract}
Giriş
¡ ' Treter taşlarının toplumun yaklaşık \%15'inde görüldüğü tahmin edilmekte ve tüm ürolitiyazis olgularının \%20'sinden sorumlu olduğu bilinmektedir (1). Üreter taşlarının tedavisinde başlıca 3 tedavi yöntemi vardır: Medikal ekspulsif tedavi (MET) ile taşın spontan atılmasını kolaylaştırmak, endoskopik taş kırma tedavisi (URS) ve şok dalgaları (SWL) ile taşın fragmantasyonu. Bu 3 tedavi yönteminin seçiminde birçok faktör rol oynamasına rağmen; en önemli parametre taş boyutu olarak kabul edilmektedir. Bu konudaki genel yaklaşım boyutu $10 \mathrm{~mm}$ 'den küçük üreter taşlarının MET ile 4-6 hafta izlenmesi ve bu süre sonunda fayda görmeyen hastaların diğer tedavi yöntemlerine yönlendirilmesi şeklindedir. Güncel kılavuzlarda da; üreter taşları için tedavi önerileri taşın boyutu ve lokalizasyonuna göre yapılmaktadır.

$\mathrm{Bu}$ makalede son bir yıl içinde üreter taşlarının minimal invaziv tedavisi alanında yapılan ve uluslararası dergilerde yayınlanan çalışmalardan öne çıkanların gözden geçirilmesi amaçlanmıştır.
\end{abstract}

\section{Şok Dalga (SWL) Tedavisi}

İlk olarak 1980'lerde tanımlanan SWL, ilerleyen yıllarda minimal invazif karakterinin yanında teknolojik gelişmelerin de yardımıyla popülaritesini artırmıştır. Yeni enerji kaynaklarının (elektromanyetik, elektrohidrolik ve piyezoelektrik) kullanıldığı SWL cihazlarının tanımlanmasıyla etkinliği artarken, işlem sırasında oluşan ağrı ve doku hasarı azalmıştır (2). Diğer tedavi yöntemlerine göre avantajları invazif bir yöntem olmaması, erişkinlerde ve bazı çocuk hastalarda anestezi gerektirmemesi, hastaların aynı gün eve gidebilmesi, güvenli bir tedavi alternatifi olması ve diğer yöntemler gibi cerrahi tecrübe gerektirmemesidir. Ancak cihazın maliyeti ve nihai taşsızlık için çoklu seans gereksinimi en büyük dezavantajlarını oluşturmaktadır (3).

Taş boyutu SWL tedavisinin başarısını etkileyen en önemli faktördür. Avrupa Üroloji Derneği (EAU) Kılavuzu'nda proksimal üreter taşlarında boyut $<1 \mathrm{~cm}$ ise; ilk seçenek $\mathrm{SWL}$, ikinci secenek URS, $>1 \mathrm{~cm}$ ise URS veya $S W L$, distal üreter taşlarında boyut $<10 \mathrm{~mm}$ ise URS veya $S W L,>1 \mathrm{~cm}$ ise ilk seçenek URS ikinci seçenek SWL olarak önerilmektedir.

İki cm'nin altındaki proksimal üreter taşlarının tedavisinde SWL ile URS'nin karşılaştırıldığı prospektif ve randomize bir çalışmada hastalar taş boyutuna göre gruplandırılmıştır (3). Çalışmanın sonucuna göre $1 \mathrm{~cm}$ 'den küçük üreter taş1 olan hastalarda SWL ve URS aynı etkinlik ve güvenlikte bulu- nurken, 1-2 $\mathrm{cm}$ arası proksimal üreter taşlarının tedavisinde URS düşük ek tedavi ve yüksek başarı ile ön plana çıkmıştır. Ayrıca bu çalışmada taş kompozisyonunun SWL veya URS sonuçlarına etki etmediği ve taş boyutu ile komplikasyon oranının anlamlı bir birlikteliği olmadığı gösterilmiştir (3).

Yapılan çalışmalarda distal üreter taşlarında da URS'nin başarı oranının SWL'ye göre daha iyi olduğu gösterilmiştir. SWL'nin etkinligini artırmak amacıyla supin pozisyonda; şok dalgalarının transgluteal olarak iskiadik foramenden geçerek üretere hedeflenmesiyle daha başarılı sonuçlar alındiğı gösterilmiştir. Bu yöntemle taş-cilt mesafesi kısaltılmış, sok dalgalarının diğer dokular tarafından daha az emilmesi sağlanmış ve üreter taşı bu açıdan daha kolay görüntülenebilmiştir (4). Bu yöntem teorik olarak avantajlar sunsa da; SWL yapan kişinin tecrübesinin de önemli olduğu unutulmamalıdır. Prospektif randomize çalışmalar ile distal üreter taşlarında farklı yöntemlerin sonuçlarının karşılaştırılması gerekmektedir.

SWL sırasındaki şok dalgalarının frekansı da son dönemdeki çalışmalara konu olmuştur. Böbrek taşlarında farklı frekansların (60, 90 ve 120/dk) etkinliği araştırılmış, düşük frekanslarda daha başarılı sonuçlar alındığı gösterilmiştir. Distal üreter taşlarına SWL'nin uygulandığı prospektif randomize bir çalışmada düşük frekans (60/dk) ile tedavi edilenlerde yüksek frekansla (80/dk) tedavi edilenlere göre daha yüksek başarı elde edilmiştir. Ancak yazarlar 7 mm'den büyük taşlarda anlamlı istatistiksel fark gösterememiştir (5). Sonuçta SWL başarısı tek bir faktörle ilişkili olmayıp, hastaya (BMI, taş-cilt mesafesi, anatomik faktörler) ve taşa (dansitesi, boyutu, lokalizasyonu, yüzeyi, impakte olup olmaması) ilişkin faktörlerinin karmaşık ilişkisinden etkilenmektedir.

Yapılan diğer bir çalışmada üreter taşlarında tedavinin gecikmesinden kaynaklanan artmış komplikasyon ve morbidite riskini azaltmak amaciyla acil SWL tedavisi uygulanmıştır. Acil SWL, renal kolik atağından sonraki ilk 72 saat (ideali 24 saat) içerisinde $1 \mathrm{~cm}^{\prime}$ den küçük, tek üreter taş1 ve obstrüksiyonu olan hastalarda uygulanan bir işlemdir. $\mathrm{Bu}$ yöntemde üreter taşlarına impakte olmadan müdahale edilmekte; böylece iş gücü kaybı, hastane acil servis ziyaretleri azaltılmakta ve SWL işleminin başarısının artırılması amaçlanmaktadır (6). Ancak konservatif yaklaşımdan fayda görebilecek hasta gruplarına uygulandığı için ekonomik bir yöntem değildir. Hangi hastaların konservatif yaklaşım ile sorunsuz tedavi edilebileceği sorusu henüz tam olarak netlik kazanmadığı için, acil SWL tedavisi henüz klavuzlara girmiş bir tedavi değildir.

Çocuklarda ilk defa 1986 yılında uygulandığı bildirilen 
SWL bu grup hastalarda da; yaygın bir uygulama alanı bulmuştur. Ancak SWL'nin doku hasarı oluşturucu etkisinin hayvan modellerinde gösterilmiş olması, bu tedavinin çocuklardaki en önemli çekince sebeplerinden birisi olmuştur. Radyasyon maruziyeti, geç dönem ortaya çıkan potansiyel komplikasyonlar (diabetes mellitus, hipertansiyon ve böbrek yetmezliği) en önemli endişelerdir. Bu konuda geçmiş yıllarda farklı sonuçlar bildiren çalışmalar yayınlanmıştır. Son olarak 1990-2009 arasında, yalnızca SWL tedavisi gören, en az 2 yıllık takip süresi olan 70 pediatrik hastanın değerlendirildiği çalışmada hastaların hiç birinde hipertansiyon veya diabet görülmemiştir. Ancak çocuklarda muhtemel renal hasarı minimalize etmek için düşük enerji ve düşük şok dalga sayısı kullanılması önerilmektedir (7).

\section{Üreteroskopi (URS)}

Endoskopik üreter taşı tedavisinin teknolojik yeniliklerle birlikte başarı oranı artmış komplikasyon oranları ise genel olarak azalmıştır. Güncel EAU kılavuzlarında $1 \mathrm{~cm}$ 'den büyük üst üreter taşları hariç, tüm üreter taşlarında ilk basamak minimal invaziv tedavi seçeneği olarak URS önerilmektedir (8). Bunda şüphesiz Holmium:YAG lazerin kullanımının katkısı inkar edilemez bir gerçektir. Yayınlanan bir metaanalizin sonuçlarına göre Ho:YAG lazer, pnömotik litotriptöre göre daha etkin ve güvenli bulunmuş; ayrica lazer kullanımının taş retropulsiyonunu ve DJ gereksinimini azalttığ gösterilmiştir (9).

URS işlemi çoğu hafif olmak üzere \%9-25 komplikasyon riskine sahiptir. Taşın proksimal üreterde olması, tecrübesizlik, taşın boyutunun artması, impakte olması ve geniş çaplı üreteroskop kullanımı komplikasyonları artıran sebeplerdir. Daha küçük çaplı üreteroskop kullanımı ile komplikasyon oranının \%5-9 azaltılabileceği bildirilmiştir. Ülkemizde yapılan retrospektif bir çalışmada 4.5Fr mini üreteroskop ile standart 8.5Fr üreteroskop ile yapılan URS işlemleri retrospektif olarak karşılaştırılmış, benzer ameliyat süresi ve taşsızlık saptanmıştır. Gruplar arasında genel komplikasyon oranları benzer olsa da; hematüri ve mukozal yaralanma gibi komplikasyonlar miniURS grubunda anlamlı olarak düşük bulunmuştur (10). Mini üreteroskop özellikle okul çağı öncesi çocuk hastalar için oldukça önemliyken, erişkin hastalarda ilk etapta kullanılacak enstrüman olmadığı; ancak zorlu olgular için hazırda bulunması gerektiğini düşünmekteyiz. Mini üreteroskopların yüksek maliyetinin yanısıra, tek ve küçük çalışma kanalının bulunması ve sınırlı görüntü alanı sağlaması en büyük dezavantajlarıdır.

Gebe hastalarda URS, anne için var olan risklerin yanında; erken doğum riski yaratmasından dolayı fetüs için de; ürolojinin zorlu olgularından biri olarak kabul edilmektedir. Önceleri gebe hastalarda 22. gebelik haftasına kadar üreteral stentten bile sakınılıp, nefrostomi yerleştirilmesi önerilirken; artan tecrübeyle birlikte gebelerde URS başarıyla uygulanan bir işlem haline gelmiştir. Tek merkezden geniş bir serinin sunulduğu bir çalışmada, tecrübeli eller tarafından yapılan URS işleminin gebe olan ve olmayan hastalarda, başarı ve komplikasyon açısından benzer olarak bulunmuştur. Ayrıca, gebelik hormonlarına bağlı olarak üreterdeki dilatasyondan dolayı ek dilatasyon işlemi gereksiniminin de anlamlı olarak azaldığı bildirilmiştir (11). Taş kırma amacıyla pnömotik yöntemi kullandıklarını bildiren çalışmalar olsa da; erken doğum eylemini tetikleme riskinden dolayı bu hastalarda
Ho:YAG lazerin en güvenli yöntem olduğu aşikardır. Genel kontrendikasyonlara ilave olarak, yeterli obstetrik bakımın yapılama olanağının bulunmadığı merkezlerde gebelere URS'nin yapılmaması gerektiği bildirilmiştir (12).

Endoskopik ürolitiyazis tedavisi özellikle yeni alet ve cihaz gelişmelerine açık bir alandır. Özellikle proksimal üreter taşlarının endoskopik tedavisi sırasında taş fragmanlarının retropulsiyonunu önlemek için endüstri yeni malzemeler üretip kullanıma sunmaktadır. Bu malzemelerin taş retropulsiyonunu önlemelerinin yanında ameliyat süresini kısalttıkları, ek tedavi oranını azalttıkları gösterilmiştir $(13,14)$. Bu cihazların kullanımının ekonomik olup olmadığını araştıran bir çalışma sonucunda; kullanımının daha ekonomik olduğu sonucuna varılmıştır (15). Ancak bu çalışma gerçek hastalarla değil, karar analiz modeli üzerinde literatürdeki komplikasyon oranları göz önünde bulundurularak yapılmıştır. Bu modele göre üst sisteme kaçan fragmanların tedavisinde ek tedavi olarak URS veya SWL yapılacağı öngörülmüştür. Ancak bu hastalara uygulanabilecek tedavi yöntemleri arasında PNL olduğu gibi; cerrahi yapmaksızın takip seçeneği ve medikal tedavi de vardır. Ayrıca bu çalışmada cihaz ve tedaviler için ön görülen fiyatların ülkeler arasında değiştiği, bazı merkezlerde bu aletlerin steril edilerek tekrar kullanıldı$\breve{g}_{1}$ da bir gerçektir.

Üreteroskopi, cerrahi olarak SWL'ye kiyasla daha yüksek başarıya sahipken, hasta memnuniyetinin karşılaştırıldığ çalışmada sonuçların SWL lehine olduğu görülmüştür (12). İşe dönüş süresi ve alt üriner sistem semptomları özellikle URS grubunda daha olumsuzdur. Yazarlar bu sonucu URS sonrası yerleştirilen üreteral stente bağlamışlardır. Ancak şunu da belirtmek gerekir ki; çalışmada URS yapılan 95 hastanın tamamına double J stent yerleştirilmiştir ki; bu da semptomların URS'nin kendisinden çok stente bağlı olabileceği sonucunu doğurmaktadır.

URS tekniği cerrahın tecrübesine göre değişmekle beraber radyasyon konusunda duyarlılığın artmasıyla "işlem sırasında fluroskopi muhakkak gerekli mi?" sorusu da gündeme gelmiştir. Yapılan çalışmalarda URS sırasında fluroskopi ile alınan radyasyon dozlarının azımsanmayacak düzeyde olduğu, hastaların tanı-takip süresince görüntüleme yöntemlerinden aldıkları da ilave edilirse ciddi radyasyona maruz kaldıkları gösterilmiştir. Son dönemde yapılan bir çalışmada, tecrübeli cerrahlar tarafından URS yapılan 93 hastanın yalnızca 7'sinde fluroskopinin sinırlı bir şekilde kullanıldığı ve literatürdeki sonuçlara benzer başarı ve komplikasyon oranlarına ulaşıldığı bildirilmiştir. Sonuç olarak yazarlar fluroskopinin endoüroloji için önemli bir görüntüleme yöntemi olduğunu ancak sinırlı ve gerekli durumlarda kullanılması gerektiğini vurgulamışlardır $(16,17)$.

Endoskopik üreter taşı tedavisinin komplikasyonları literatürde farklı şekillerde sınıflandırılmıştır. Kimi yazar kronolojik sırasına göre (intraoperatif, postoperatif) kimi yazar da ciddiyetine göre (minor ve major) şekilde sınıflamıştır. URS'nin postoperatif komplikasyonları Clavien sistemi ile siniflandirllirken, daha ciddi ve dramatik olan intraoperatif komplikasyonları sinıflamak için ise; maalesef bir sınıflama sistemi kullanılmamaktadır. Bu sorunu gören bir araştırmacı, ürolojik laparoskopide intraoperatif komplikasyonları sınıflamak için kullanılan Satava sistemini URS'ye adapte etmiş, 1208 URS işlemindeki intraoperatif komplikasyonları bu sistem ile derecelendirmişlerdir (18). Bu sisteme göre hiç bir tedavi gerekmeyen komplikasyonlar 1 . derece, endoskopik 
tedavi gerektiren komplikasyonlar 2. derece (2a, aynı seans sırasında, $2 b$ ek seans gerektiren), açık cerrahi veya laparoskopik cerrahiye geçiş gerektirenler ise 3. derece olarak sınıflandırılmıştır. Oldukça sık uygulanan bir endoskopik işlem olan URS'nin merkezler arasında cerrahi sonuçlarının kolaylıkla karşılaştırılabilir olması için uygulaması kolay, basit bir dereceleme sistemi gerekmektedir ve Satava sistemi uygun olabilir. Ancak bu yöntemin bir validasyon çalışmasına ihtiyacı vardir.

Üreter taşları çocuklarda erişkinlerde olduğu kadar sık olmayıp, üriner sistem taşlarının ancak \%7'sini oluşturur. Çocuklarda üreterin oldukça dar ve narin olmasından dolayı perforasyon, iskemi, darlık ve potansiyel VUR riski nedeniyle önceleri URS sinırlı olgularda uygulanmaktaydı. Ancak üreteroskop ve çalışma elemanlarının incelmesi ve lazerin kullanıma girmesiyle URS çocuk hastalarda da; başarılı ve güvenli bir şekilde günümüzde uygulanmaktadır. Çocuk hastalarda URS sonuçlarına etki eden faktörlerin değerlendirilmesi amacıyla 32 hastada 54 URS işleminin retrospektif olarak incelendiği bir çalışmada hasta yaşının ve taş analizinin başarı üzerinde etkili olduğu gösterilmiştir (19). Özellikle sistin taşı olan ve 5 yaşından küçük hastalarda taşsızlık oranının düşük, komplikasyon ve açı̆̆a geçiş oranının da yüksek olduğu bildirilmiştir. Ortalama yaşı 4.7 yıl olan 104 çocuk hastada yapılan 128 URS işleminin sonuçlarının analiz edildiği diğer bir çalışmada da; özellikle yaşın $(<2$ yıl), taş lokalizasyonunun (proksimal taşlar) ve üreter çapının URS sonuçlarında etkili olduğu rapor edilmiştir. Çok değişkenli analiz sonucunda ise; bu faktörlerden yalnızca yaşın etkili olduğu vurgulanmıştır (20). Ancak bu çalışmada yazarlar 7.5Fr üreteroskop kullanmışlardır. Daha küçük yaştaki çocuklarda 4.5Fr çaplı miniURS kullanmanın başarıyı artıracağına inanmaktayız. Ayrıca, küçük yaştaki çocuklarda endoskopik üreter taşı tedavisi bu konuda tecrübesi ve teknik donanımı olan merkezlerde yapılmalıdır.

Üreter taşları tedavi edilmediği takdirde idrar akışını tıkayıp, üst sistemde hidronefroz, enfeksiyon, fonksiyon kaybı ve hatta sepsis sonucu ölüme bile yol açabilir. Obstrükte sistemin tedavisi klasik olarak o sistemin drene; yani dekomprese edilmesidir. Üreter taşına bağlı ürosepsis tablosu ile hastaneye başvuruların incelendiği bir çalışmada toplam 1712 hasta retrospektif olarak değerlendirilmiş, cerrahi dekompresyon yapılmayan hastaların hastanede medikal tedavi altına alındıkları dönemde 2 kat daha fazla ölüm riski taşıdıkları gösterilmiştir (21). Amerika Birleşik Devletleri'nde yapılan bu çalışmada bu hastaların \%25'ine herhangi bir dekompresyon yöntemi uygulanmamıştır. Dekompresyon yöntemi olarak hastaların \%70.1'inde üreteral stent, \%25.9'unda ise perkütan nefrostomi tercih edilmiştir. "Hangi dekompresyon yönteminin seçilmesi daha iyi olur?" sorusunu araştıran güncel bir çalışmada ise; her iki yöntemin de (üreteral J stent ve perkütannefrostomi) etkin olduğu ancak taşı yükü ve klinik tablonun daha ağır olduğu hastalarda nefrostominin daha çok tercih edildiği ortaya konulmuştur (22). Sepsis tablosuyla başvuran bir hastaya lokal veya genel anestezi altında üreteral stent yerleştirmeye çalışmak, anestezi açısından sakıncalı olabilir. Ayrıca obstrükte ve dolayısıyla üst sistemi enfekte olan bir hastaya klavuz tel üzerinden stent yerleştirmek zor olacağı gibi; URS ile stent koymaya çalışmak da; zaten yüksek basınçlı üst sistemin basıncını daha da artırarak sepsis tablosunun ağırlaşmasına sebep olabilir. Bu çalışma da göstermiştir ki; klinik tablonun ağır olduğu hastalarda bask1- layıcı antibiyoterapi sonrası perkütan nefrostomi ile sistemi drene etmek daha efektiftir.

Üreteroskopik taş tedavisi konusunda yeniliklerden bahsedilirken atlanmaması gereken en önemli yenilik ve ülkemizin de övünç kaynağı olan robot yardımlı fleksibl üreteroskopi'dir. Prof. Sağlam ve ekibi tarafından geliştirilip, uluslar arası üroloji camiasında tanıtımı yapılan ve "Avicenna" ismi verilen bu robot sayesinde fleksibl üreteroskop ile taş fragmentasyonu işlemi başarıyla gerçekleştirilebilmektedir. Robot yardımlı fleksibl üreteroskopi işlemini tecrübe eden bir ekip olarak, robotun cerrah konforuna pozitif katkı yapacağını düşünmekteyiz. Daha somut veriler sunmak ve klinik karşılaştırmalar yapmak için prospektif randomize çalışmaların devam ettiği bilinmektedir.

\section{Perkütan Antegrad Üreterolitotripsi}

İmpakte ve büyük üst üreter taşları ürologlar için tedavisi zor olgulardan biri olarak kabul edilmektedir. Tedavisinde SWL, URS, PNL, laparoskopik hatta açık cerrahi yerine göre kullanılabilir. SWL'nin başarısı 1cm'den büyük ve impakte üreter taşlarından oldukça düşüktür.

Üst üreter taşlarında uygulanan bir diğer tedavi yöntemi de; perkütan olarak renal akses sağlanıp bu traktan toplayıcı sisteme ve oradan da üretere ilerleyerek yapılan perkütan antegrad üreterolitotripsidir. Genellikle retrograd yolla ulaşılamayan veya ulaşılsa bile lazerle fragmentasyonu zaman alan, ileri derecede impakte olmuş, $1 \mathrm{~cm}$ 'den büyük üst üreter taşlarında uygulanabilecek bir yöntemdir.

Proksimal üreterdeki impakte üreter taşları için URS'nin komplikasyon oranının \%2-25 arasında olduğu bildirilmiştir $(23,24)$.Yine en morbid komplikasyon olan üreter avülsiyonu riskinin özellikle impakte olmuş üreter taşlarında arttığı unutulmamalıdır. Antegrad yöntem URS'ye göre daha invaziv bir yöntem olarak düşünülse de; impakte üst üreter taşlarında URS'nin neden olabileceği riskler göz önüne alındığında, antegrad yöntem etkin ve güvenli bir seçenek olarak önümüze çıkmaktadır. Ayrıca şunu da unutmamak gerekir ki; proksimal üreter taşlarında URS ve PNL'nin karşılaştırıldığ çalışmalarda başarı oranı PNL grubunda anlamlı derecede yüksektir (25).

İmpakte üst üreter taşı nedeniyle obstrükte, aşırı dilate olmuş ve enfekte üst sistemin acil drenajı amaciyla lokal anestezi altında perkütan nefrostomi yerleştirilmesiyle, üst sistemin basıncı düşürülüp, küratif tedavi için zaman kazanılarak bu sırada gerekli medikal tedavi sağlanabilir. İkinci aşamada ise; enfeksiyon kontrol altına alındıktan sonra aynı veya bir başka antegrad perkütan trakt ile dilate ve basıncı düşmüş toplayıcı sisteme girilerek impakte proksimal üreter taşı tedavi edilebilir. Bu konuda yayınlanan güncel bir çalışmada proksimal üreter taşı olan seçilmiş acil hastalara ilk etapta perkütan nefrostomi yerleştirilmiş ve daha sonra 2. seansta $18 \mathrm{Fr}$ mini nefroskop kullanılarak antegrad üreteroskopi yapılmış ve \%100 taşsızlık oranı sağlanmıştır (26). Hatta daha küçük çaplı (12-16Fr) bir trakttan 8-10Fr çapında üreteroskop kullanılarak bu işlem gerçekleştirilebilmektedir. Bu yöntemle hem üretere hem de; renal toplayıcı sisteme rahatlıkla ulaşılabilmektedir. Dar açılı alt kaliksten rijit alet kullanarak üretere ulaşmak mümkün olmayacağı için; akses için orta-üst kaliks grubu daha uygundur. Ancak bu tekniğin kanama diatezi olan hastalarda kontrendike olduğu ve URS'ye göre daha invazif bir yöntem olduğu unutulmamalıdır. 


\section{Laparoskopik Üreterolitotomi}

Birincil basamak tedavilerin (URS, SWL veya PNL) başarısız olduğu veya başarısız olacağı öngörülen olgularda büyük üst-orta üreter taşlarında yeterli cerrahi tecrübe de varsa; laparoskopik cerrahi tercih edilebilir. Güncel klavuzlarda laparoskopik cerrahi ürolitiyazis tedavisinde açık cerrahinin alternatifi olarak ya seçilmiş olgularda; ya da diğer tedavi yöntemlerinin başarısızlığında önerilen bir tedavi modalitesidir.

Bir cm'den büyük üst üreter taşları için en az invazif olan cerrahi yöntem hiç kuşkusuz URS'dir. Operasyon süresi, kan kaybı ve hastanede kalış açısından URS üstün olsa da; başarı oranı PNL ve laparoskopiye göre daha düşüktür. URS'nin başarısız olduğu durumlarda PNL veya laparoskopik yaklaşım uygun tedavi seçenekleridir. Üst üreter taşları için uygulanan URS, PNL ve laparoskopik üreterolitotominin retrospektif karşılaştırıldığı çalışmada başarı oranı PNL grubunda anlamlı ölçüde yüksek saptanmıştır (27). Başarı oranı URS grubundan en düşük bulunmuştur. Ayrica operasyon ve hastanede kalış süresi ile ortalama kan kaybı laparoskopi grubunda anlamlı şekilde yüksek bulunmuştur. Retrospektif, çok merkezli olması ve düşük hasta sayısı çalışmanın değerini düşürmektedir.

Üreter taşları için uygulanan laparoskopik cerrahi retroperitoneal veya transperitoneal olarak gerçekleştirilebilir. Şimdiye kadar yapılan çalışmalar tekniklerin birbirlerine üstünlügünü ortaya koyamamıştır. Geçtiğimiz yıl yayınlanan prospektif randomize bir çalışmada her iki yöntem karş1laştırılmış ve başarı açısından benzer sonuçlar bulunmuştur. Ancak transperitoneal yöntemin uygulandığı hastalarda ağrl, ağrı kesici ihtiyacı, ileus ve hastanede kalış süresinin anlamlı derecede daha yüksek olduğu gözlenmiştir (28).

Son yillarda daha iyi kozmetik sonuçlar almak amaciyla tek portlu laparoskopik (LESS) cerrahi uygulanmaya başlanmış ve başarılı sonuçlar alınmıştır. Retroperitoneal olarak uygulanan LESS hem kozmetik açıdan iyi sonuçlar vermekte; hem de transperitoneal işlemin risklerini taşımamaktadır. Ülkemizden yapılan çalışmada retroperitoneal olarak LESS ve konvansiyonel laparoskopik üreterolitotomi uygulanan hastalar retrospektif olarak karşılaştırılmıştır (29). LESS uygulanan grupta ameliyat sonrası ağrı, analjezik gereksinimi, normal aktivitelere dönüş ve skar sayısı anlamlı ölçüde düşük saptanmıştır. Ancak bu yöntemin özellikle de; retroperitoneal alan gibi dar bir alanda uygulanmasi; daha fazla cerrahi tecrübe gerektirmekte ve bu da muhtemelen tekniğin en önemli dezavantajını oluşturmaktadır.

Günümüzde robot yardımlı laparoskopik cerrahi özellikle böbrek ve prostat kanserleri cerrahisinde sıkça uygulanır hale gelmiştir. Distal üreter taşlarının laparoskopik cerrahisi anatomik nedenlerden dolayı daha zorludur. Robot yardım1ı laparoskopik cerrahi, laparoskopiye kıyasla daha hızlı ve cerrah için daha konforlu bir ameliyat olarak sunulmaktadır (30). Şüphesiz maliyet bu yöntemin en büyük dezavantaj1dir.

\section{Sonuç}

Günümüzde hastalar için daha başarılı, güvenli sonuçlar sunan minimal invazif ürolitiyazis tedavisi teknolojik yeniliklerle birlikte daha da gelişecektir. Endoürologlar bütün bu tedavi alternatiflerini imkânları ve tecrübeleri nispetinde seçip uygun hastalar için uygulayacaklardır. Bu yeniliklere uzak kalmamak için güncel teorik ve pratik eğitim endoürologlar için mutlaka gereklidir.

\section{Kaynkaklar}

1. Dellabella M, Milanese G, Muzzonigro G. Randomized trial of efficacy of tamsulosin, nifedipine and phloroglucinol in medical expulsive theraphy for distal ureteral calculi. J Urol. 2005; 174: 167-172.

2. Neisius A, Wöllner J, Thomas C, Roos FC, Brenner W, Hampel C, Preminger GM, Thüroff JW, GillitzerR. Treatment efficacy and outcomes using a third generation shockwave lithotripter.BJU Int. 2013;112(7):972-81.

3. Kumar A, Nanda B, Kumar N, Kumar R, Vasudeva P, Mohanty NK. A Prospective Randomized Comparison between Shockwave Lithotripsy and SemirigidÜreteroscopy for Upper Üreteral Stones $<2 \mathrm{~cm}$ : A Single Center Experience.J Endourol. 2013 Sep 12.

4. Phipps S, Stephenson C, Tolley D. Extracorporeal shockwave lithotripsy to distal üreteric stones: the transgluteal approach significantly increases stone-free rates. BJU Int. 2013;112(2):E129-33.

5. Anglada-Curado FJ, Campos-Hernández P, CarrascoValiente J, Anaya-Henares F, Carazo-Carazo JL, AlvarezKindelán J, Regueiro-López JC, Requena-Tapia MJ. Extracorporeal shock wave lithotripsy for distal üreteral calculi: improved efficacy using low frequency.Int J Urol. 2013;20(2):214-9.

6. Panah A, Patel S, Bourdoumis A, Kachrilas S, Buchholz $\mathrm{N}$, Masood J. Factors predicting success of emergency extracorporeal shockwave lithotripsy (eESWL) in üreteric calculi--a single centre experience from the United Kingdom (UK). Urolithiasis. 2013;41(5):437-41.

7. El-Nahas AR, Awad BA, El-Assmy AM, Abou El-Ghar ME, Eraky I, El-Kenawy MR, Sheir KZ. Are there longterm effects of extracorporeal shockwave lithotripsy in paediatric patients? BJU Int. 2013;111(4):666-71.

8. Turk C, Knoll T, Petrik A, Sarica K, Skolarikos A, Straub M, Seitz C. Guidelines on Urolithiasis, European Association of Urology, 2013.

9. Yin $X$, Tang Z, Yu B, Wang Y, Li Y, Yang Q, Tang W. Holmium: YAG laser lithotripsy versus pneumatic lithotripsy for treatment of distal üreteral calculi: a metaanalysis.J Endourol. 2013;27(4):408-14.

10. Atis G, Arikan O, Gurbuz C, Yıldirim A, Erol B, Pelit S, Ulus I, Caskurlu T. Comparison of different üreteroscope sizes in treating üreteral calculi in adult patients. Urology. 2013;82(6):1231-5.

11. Bozkurt Y, Soylemez H, Atar M, Sancaktutar AA, Penbegul N, Hatipoglu NK, Bodakci MN, Evsen MS. Effectiveness and safety of üreteroscopy in pregnant women: a comparative study. Urolithiasis. 2013;41(1):3742.

12. Park J, Shin DW, Chung JH, Lee SW. Shock wave lithotripsy versus üreteroscopy for üreteral calculi: a prospective assessment of patient-reported outcomes. World J Urol. 2013;31(6):1569-74.

13. Wu JA, Ngo TC, Hagedorn JC, Macleod LC, Chung BI, Shinghal R. The accordion antıretropulsive device improves stone-free rates during üreteroscopic laser lithotripsy. J Endourol. 2013;27(4):438-41. 
14. Elashry OM, Tawfik AM.Preventing stone retropulsion during intracorporeal lithotripsy.Nat Rev Urol. 2012;9(12):691-8.

15. Ursiny $\mathrm{M}$, Eisner $\mathrm{BH}$. Cost-effectiveness of antiretropulsion devices for üreteroscopic lithotripsy. J Urol. 2013;189(5):1762-6.

16. Hsi RS, Harper JD. Fluorolessüreteroscopy: zero-dose fluoroscopy during üreteroscopic treatment of urinarytract calculi. J Endourol. 2013;27(4):432-7.

17. Tepeler A, Armagan A, Akman T, Sılay MS, Akçay M, Başıbüyük I, Erdem MR, Önol ŞY. Is fluoroscopic imaging mandatory for endoscopic treatment of üreteral stones? Urology. 2012;80(5):1002-6.

18. Tepeler A, Resorlu B, Sahin T, Sarikaya S, Bayindir M, Oguz U, Armagan A, Unsal A. Categorization of intraoperative üreteroscopy complications using modified Satava classification system. World J Urol. 2014;32(1):131-6.

19. Tıryaki T, Azili MN, Özmert S. Üreteroscopy for treatment of üreteral stones in children: factors influencing the outcome.Urology. 2013;81(5):1047-51.

20. Elsheemy MS, Maher A, Mursi K, Shouman AM, Shoukry AI, Morsi HA, Meshref A. Holmium:YAG laser üreteroscopic lithotripsy for üreteric calculi in children: predictive factors for complications and success. World J Urol. 2013 Aug 25

21. Borofsky MS, Walter D, Shah O, Goldfarb DS, Mues AC, Makarov DV. Surgical decompression is associated with decreased mortality in patients with sepsis and üreteral calculi. J Urol. 2013;189(3):946-51.

22. Goldsmith ZG, Oredein-McCoy O, Gerber L, Bañez LL, Sopko DR, Miller MJ, Preminger GM, Lipkin ME. Emergent üreteric stent vs percutaneous nephrostomy for obstructive urolithiasis with sepsis: patterns of use and outcomes from a 15-year experience. BJU Int. 2013;112(2):E122-8.

23. Kijvikai K, Haleblian GE, Preminger GM, et al. Shock wave lithotripsy or üreteroscopy for the management of proximal üreteral calculi: an old discussion revisited. J Urol. 2007;178: 1157-1163.

24. Wolf JS Jr. Treatment selection and outcomes: üreteral calculi. UrolClin North Am. 2007;34:421-430.

25. Xiao-jian G, Jian Lin L, Yan X. Treatment of large impacted proximal üreteral stones: randomized comparison of minimally invasive percutaneous antegradeüreterolithotripsy versus retrograde üreterolithotripsy.World J Urol. 2013;31(6):1605-10.

26. Aravantinos E, Anagnostou T, Samarinas M, Ioannides K, Ziavliakis K, Ntafos A, Melekos M. Two-step minipercutaneousüreterolithotripsy under multimodal analgesia for complicated impacted calculi in proximal üreter.Urology. 2013;81(6):1147-52.

27. Zhu H, Ye X, Xiao X, Chen X, Zhang Q, Wang $H$. Retrograde, antegrade, and laparoscopic approaches to the management of large upper üreteral stones after shockwave lithotripsy failure: a four-year retrospective study.J Endourol. 2014;28(1):100-3.

28. Singh V, Sinha RJ, Gupta DK, Kumar M, Akhtar A. Transperitoneal versus retroperitoneal laparoscopic üreterolithotomy: a prospective randomized comparison study. J Urol. 2013;189(3):940-5.

29. Tugcu V, Simsek A, Kargi T, Polat H, Aras B, Taşc1 AI. Retroperitoneal laparoendoscopic single-site üreterolithotomy versus conventional laparoscopic üreterolithotomy.Urology. 2013;81(3):567-72.

30. Dogra PN, Regmi SK, Singh P, Saini AK, Nayak B. Lower üreteral stones revisited: expanding the horizons of robotics. Urology. 2013;82(1):95-9.

Yazışma Adresi:

Abdulkadir Tepeler

Bezmialem Vakıf Üniversitesi, Tıp Fakültesi,

Üroloji Anabilim Dall, Adnan Menderes Bulvarl, Fatih, İstanbul

Tel: +905434935055

e-mail: akadirtepeler@yahoo.com 